\title{
Two identical copies of IS1246, a 1275 base pair sequence related to other bacterial insertion sequences, enclose the $x y l$ genes on TOL plasmid pWWO
}

\author{
B. Rajasekhar Reddy, † Linda E. Shaw, Jon R. Sayers and \\ Peter A. Williams
}

Author for correspondence: Peter A. Williams. Tel: +44248 382363. Fax: + 44248 370731. e-mail: BSS003@BANGOR.AC.UK

School of Biological Sciences, University of Wales, Bangor LL57 2UW, UK

\begin{abstract}
Two identical direct repeats of a 1275 bp sequence, designated IS1246, encompass the $x y l$ genes, which determine the catabolism of toluene, $m$ - and p-xylenes to central metabolites, on the TOL catabolic plasmid pWWO. IS1246 has a terminal inverted repeat of 12 bp (5'GGGCACCTCGAA3') and contains a major open reading frame of $\mathbf{2 8 0}$ codons. This ORF shows significant homology with ORFs encoded by a number of bacterial insertion sequences from Bacteroides, Neisseria and Escherichia coli.
\end{abstract}

Keywords: TOL plasmid pWW0, insertion sequences IS1246, toluene-xylene catabolism, Pseudomonas putida, catabolic plasmid
The $117 \mathrm{kbp}$ TOL plasmid pWW0 confers the ability to grow on the aromatic hydrocarbon toluene and some alkylsubstituted toluenes in host Pseudomonas putida strains (Worsey \& Williams, 1975; Kunz \& Chapman, 1981). The 18 catabolic structural genes are in two adjacent operons ( $x y l C M A B N$ and $x y / X Y Z L T E G F J Q K I H)$, the expression of which is regulated by the products of two genes $x y / R$ and $x y / S$ : all the $x y /$ genes are clustered on a region consisting of less than one-third of the plasmid (Fig. 1; Assinder \& Williams, 1990). Two types of rearrangements of the $x y /$ gene cluster have been reported.

(a) Transposition. Two overlapping transposons, Tn4651 (56 kbp) and Tn4653 (70 kbp) carry the $x y /$ genes as their central portion (Tsuda \& Iino, 1987, 1988). Both are class II (Tn3-like) transposons which share tnpT, tnpS and res genes but have individual $\operatorname{tn} p \mathrm{R}$ and $\operatorname{tn} p A$ genes and are bounded by terminal inverted repeats of 46 bp ( $\operatorname{Tn} 4651$ ) and 38 bp (Tn4653) (Tsuda et al., 1989). Both transposons confer the toluene ${ }^{+}$growth phenotype upon Pseudomonas hosts.

(b) Deletion. The $x y /$ genes can be lost from $\mathrm{pWW0}$ by spontaneous deletion (Bayley et al., 1977) forming a cryptic transmissible plasmid pWW0-8 (Downing et al., 1979). The deletion is of a specific $39 \mathrm{kbp}$ fragment and

\footnotetext{
†Present address: Department of Microbiology, Sri Krishnadevaraya University, Anantpur-515003, Andhra Pradesh, India.

The GenBank accession numbers for the insertion sequences and their flanking DNA reported in this paper are L11585 and L11583, respectively.
}

occurs by recombination between two apparently homologous direct repeats originally estimated to be of about $1.4 \mathrm{kbp}$ (Meulien et al., 1981). None of the transposon functions are lost from the plasmid in the deletion and the residual $17 \mathrm{kbp}$ of $\operatorname{Tn} 4651$ present (i.e. $56-39 \mathrm{kbp}$ ) can still act as a cryptic transposon Tn4652 (Tsuda \& Iino, 1987).

Determination of the nucleotide sequences of the regions encompassing both direct repeats reveals they are identical repeats of $1275 \mathrm{bp}$ (Fig. 2) with perfect inverted terminal repeats of $12 \mathrm{bp}$ of $5^{\prime}$ GGGCACCTCGAA3' which are not homologous to the terminal repeats of either of the TOL transposons. Comparison of the 1275 bp nucleotide sequence and all potential reading frames with the nucleotide and inferred protein databases was performed using the BLAST server (National Center for Biotechnology Information, Bethesda, USA) (Altschul et al., 1990). The DNA shows limited homology ( $35 \%$ identity) over a $1200 \mathrm{bp}$ region with IS1186 from Bacteroides fragilis (accession no. X72301) and with the very similar IS1168 from plasmid pIP417 of Bacteroides vulgatus (accession no. $\mathrm{X} 71444$ ).

Analysis of potential protein products shows one large open reading frame (ORF1) with an overlapping smaller open reading frame (ORF2) on the opposite strand (Fig. 2), a pattern which is found with a number of other IS sequences of similar size. The ORFs are capable of encoding proteins of 280 and 170 amino acids $(32 \mathrm{kDa}$ and $19 \mathrm{kDa}$ ), respectively. Comparison with the data- 


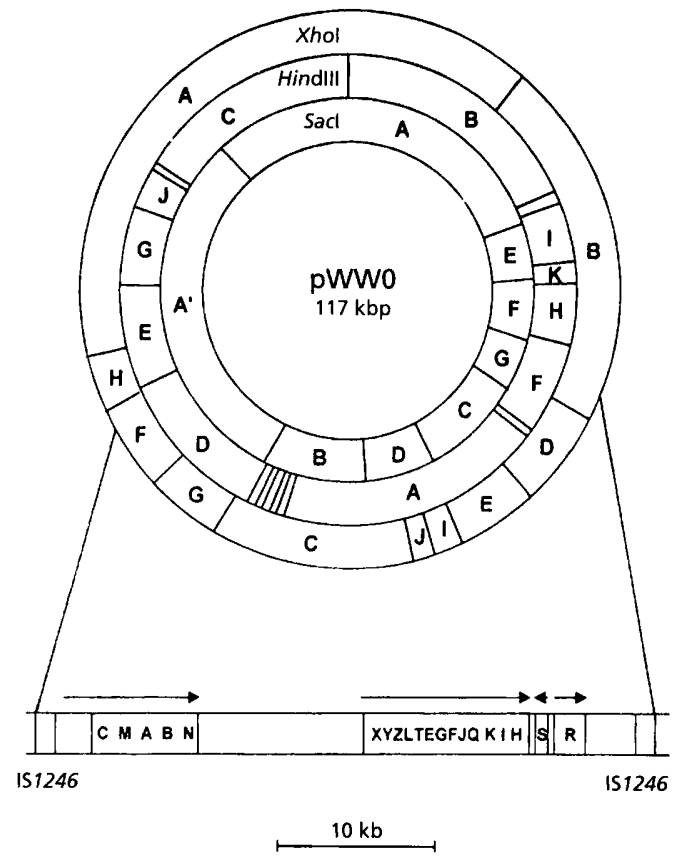

Fig. 1. Restriction map of TOL plasmid pWW0 showing relative location of the two directly repeated copies of IS1246 and the $x y /$ genes encoding the catabolism of toluene and the xylenes: the arrows represent the length and direction of the four known transcripts. The IS sequences run from left to right in the $5^{\prime}-3^{\prime}$ direction of Fig. 2. This map has been constructed from an assemblage of published restriction maps and nucleotide sequences.

\section{ECORI}

GGGCACCTCG AATAACGCGh GGTTTTCAGT GAATCCGACC GCCAAATGAT GGCCATGATC 60 GAATTCGGTT CGATTTCTGC GGCGAATCAC CGCTTTCTGG GCGGTGTCGC CCGTTTTTCT 120 PstI

TCCGAATCGC CCTCTGCAGC GGCGATTCGG CCCACTCCGG GCGTCAGAAG GCCTTGATTC 180 CCGCCTTCTG GAAGTACACC AGCCGCTTCA AGTTGTAGCA GGCCGCCATC ATCGTCATCG 240 CAAAGTTCGC GCGCCCCTGT CCGATGGTAC GGATCAACTT GCCGCCCATC TGCTCGATGC 300 TCGCGAACAC GTGCTCCACT CGGGCACGCG TCTTGGCGAT GCGGTGGTTG CGCCGTTGCT 360 KpnI

GACACTCGGA AAGGGGCTTG TTGCGGTACC CCTTCCTCTG GATCTGATTA CGATAGCCGT 420 GATCCTTGAG CCAGCCCTCC CGGTCTGCGC TGGTGTGGCC TCCGTCCGCA TAGACATCGC 480 ORF $2 \rightarrow$

GGCTCGTGTT GCTCCGGTCG ATGAGCGCAT CGAAGTGCTT GCTGTCALgG ACGCTGGCCG 540 TATCAGTCTC GAATTTGCGG ATGATCTTGT ACTTCTTGTC CACGTTGACC GAGAGCTTGT 600 AGCCGAAGTG GTTCTTGCCG TGCTTCTGCG TCCAGGTGGC ATCCGTATCC TTCTGGCGCC 660 GTTTGGCTGG CITCCAGTTA GCCGGCATCG CGCCTTCCCT GACCAGCTTG TTCTCCTCAC 720 GGCTGTTACG TTGCTTGGGA GCAGGCACCA GCGTGGCATC GACGATTTGG CCGCCGCGGG 780 CGATGAATCC GTGCCGGAGC AGTTGGGCCG TGACACCGTC GAACAGGACC TTCGCGCCGG 840 CGTCGCCGAT GCGGTTCTCG AACGTCCACA CGGTCGTTCG ATCCGGAATA TTGACCGCGC 900 TGGCCAACCC GCAGAATCGC TTGTAGCTCA TCCGGTCAAG CAACTGGTAC TCCATCTGTT 960 TORF 1

CATCCGACAG GTTGTACAGC CGCTTGAGCA CCAGAATCCG CACCATCGTC TCCGTCGGAT 1020 ACGGCGGGCG ACCGCTtgaG GGCTGACAGG GCGCGGCGCT ACCCGATCGA CTTCCGCCGC 1080 AAGTGCCGCG AAATCGATGT ACGACTCGAT CTGGGCCAGC GGATCTCCAA GCGTGTCGAT 1140 CTTCTTCCGA TGATGTTCGT CAGCGAACAG GTCCGTCTTG ATGGCAGTGC GCTTCTTCAT 1200 GGCTGGTGTC AGAGAACGAA ATCAGGACAA CGCAATTTTA CCAATCGCAG GGGGCCGAGG 1260 TTTTTCGAGG TGCCC

Fig. 2. Nucleotide sequence of IS1246. The two main open reading frames are denoted. The complement of ORF1 is shown in the $3^{\prime}-5^{\prime}$ direction from nucleotide 1006 to 164 and its start and stop codons are in underlined italics. The minor reading frame ORF2 runs in the $5^{\prime}-3^{\prime}$ direction from nucleotide 527 to 1039 and its start and stop codons are in underlined lower case. The 12 bp inverted repeats at the termini of the sequence are in bold and underlined. The characteristic EcoRI, Pstl and KpnI

ORF encoded

by:

IS1246

IS1186

IS1106

IS5

Consensus

IS1246

IS1186

IS1106

IS5

Consensus

IS1246
IS1186
IS1106
IS5

Consensus

IS1246

IS1186

IS1106

IS5

Consensus

IS1246

IS1186

IS1106

IS5

Consensus

IS 1246

IS1186

IS1106

IS5

Consensus
1 MVRILVLKRL YNLSDEQMEY QLLDRMSYKR FCGLASAVNI PDRTTVMTFE MFKILFLQRY YGLSDHQIEY QIVDRTSFRA FLGIENVDDV PDEKTIWKYR ....... MRA EAPSESVPYY SYCLR. . LRR LVLI .... . F VNPLYYFMRYR MLRIHCMQHW YNLSDGAMED ALYEIASMRL FARLSLDSAL PDRTTIMNFR -ril-lar- ynlSd-qmey ql-dr-s-rr f-g--...- pdrtti-.-r

51

100 NRIGDAGA.K VLFDGVTAQL LRHGFIAR.. GGQIVDATLV ..PAPKQRNS EALTSVGAYD KLFEDFRTFM EAKGLQFN. . EGRIIDASFV ...VAPRQRNT NWLAQDDTLS ELLELINRQL TEKGLKVEKA SAAVVDATII QTAGSKQRQA HLLEQHQLAR QLFKTINRWL AEAGVMM. .T QGTLVDATII EAPSSTK... n-l-q-ga-- -Lfe-inr-l -ekGi ….- -g-ivDAt-- --pa-kqrn-

101

150

RE . ENKLVR EGAMPANW. . KPAKRRQKDT DATWTQKHGK NHFGYKLSVN RE. . ENAKIK EGKGDELWND NPHKKFHKDV DARWTEKRGD TFYGYKOHVK IEVDEEGQIS GQTTPS. ... ....... KDK DARWIKKNGL YKLGYKQHTR $\ldots \ldots \ldots \ldots \ldots \ldots \ldots \ldots$ NKEQQRDP EMHQTKKGNQ WHFGMKAHIG re--en--i - eg--p--w-- -p-kn-qkD- darwtkK-g- -hfGykqhv-

151

200

VDKKYKIIRK FETDTASVHD SKHFDALIDR SNTSRDVYAD RGHTSADREG VDKGNKVILS YATTPANVHD SKGFEQLLDE SDKDKDLYLD AGY.. AGQES TDAE. GYTEK LHITPANAHE CKHLPPLLEG LPKGTTVYAD KGYDSAENRQ VDAKSGLTHS LVTTAANEHD LNQLGNLLHG ...EEQFVSAD AGYQGAPQRE vD-k---.- l-ttpAnvHd skh---Lldg s-k--dvyaD aGy-sA-q--

201

250

WLKDHGYRNQ IQRKGYRNKP LSECQQRRNH ..... RIAK TRARVEHVFA TVKEHGMNPI ICEKGRRNHP LTEKQKAENR ......RKSK TRCLVEHVFG HLKEHQLQDG IMRKACRNRP LTETOTKRNR ....... YLSK TRYVVEOSFC ELAEVDVDWL IAERPGKVRT LKQHPRKNKT AINIEYMKAS IRARVEHPFR -lkehg---- I--kg-rnrp Lte-q-krnr -..---rk-k tR-rVEhvFg

251

300

SIEQ.MGGKL IRTIGQGRAN FAMTMMAACY NLKRLVYF . . . QKAGIKAF FEEQSMHGLI VRTIGIVRAK ANVAMTNLTY NIFRYIQIVC NKRELAIAQ. TLHRKFRYAR AAYFGLIKVS AQSHLKAMCL NLLKAANRLS APASA ..... IIKRQFGFVK ARYKGLLKND NQLAMLFTLA NLFRADQMIR QWERSH.... -ie---g-.- - $r-i G l--a-a q-a m-a-c y$ Nl fra-q-.. -.--a-i-

Fig. 3. Multiple alignment of similar ORFs translated from several insertion sequences using PILEUP. The consensus sequence derived by analysis of the alignment by PRETTY is shown below, with identical residues in upper case and similar residues in lower case. The ORFs derived from each is element were: IS1246 (ORF1 translated from the complementary strand to base pairs 1006-164 of Fig. 2), IS1186-hypothetical protein (\$34201), IS1106-hypothetical protein (S22628), IS5-hypothetical protein (P03837).

banks reveals that ORF1 has significant homology to other ORFs encoded by IS1186 and IS1168 from Bacteroides and to a lesser extent with IS1106 from Neisseria meningitidis (Knight et al., 1992; accession no. Z11857) and IS5 from Escherichia coli (Kröger \& Hobom, 1982; accession no. J01735). The amino acid sequences of all the

sites are overlined and underlined. The DNA carrying the two IS elements was obtained by cloning fragments Sacl-G and Xhol-F (Fig. 1) in both orientations into pUC18 in its SaCl and Sall sites respectively. The approximate locations of the direct repeats were inferred from the identical configuration of EcoRI-Pstl-Kpnl sites on the two fragments (Meulien et al., 1981). A series of appropriate nested deletions were generated from all four recombinant plasmids using exonuclease III and the sequences determined by dideoxy sequencing using the two pUC universal primers. The complete sequence of each is, with its flanking DNA, was obtained from overlapping sequences on both strands. 
ORF's were analysed using the GCG suite of programs running at the Daresbury Laboratory, UK (Devereux et al., 1984). A pairwise alignment using the GAP program showed that IS1246 ORF1 and a hypothetical protein coded by IS1186 and IS1168 showed 42\% amino acid identity and an additional $17 \%$ similarity. A multiple alignment for all four sequences was produced using the program PILEUP, from which a consensus protein sequence was obtained using the default parameters of PRETTY. This shows 24 identical amino acid residues as well as many conservative replacements (Fig. 3) and the great similarity between IS1246 and IS1186 can clearly be seen as they share 112 identical amino acids in this alignment. The function of none of these putative gene products is known. A computer search using the prosite database for protein motifs (Bairoch, 1993; Devereux et al., 1984) failed to identify recognizable features.

As a result of the above similarities we propose that the directly repeated TOL plasmid sequence be designated IS1246, although we have no direct evidence that it is active as an insertion sequence.

The evidence suggests that IS 1246 plays no role in the function of the two TOL transposons: there is no homology between its terminal repeats and those of the two TOL transposons, and the reciprocal recombination between its two directly repeated copies which leads to the loss of the $39 \mathrm{kbp} x y /$ coding region, and therefore to loss of one copy of IS1246, has no effect upon the transposability of either transposon. Presumably their presence is the fortuitous result of some other event in the past history of plasmid pWW0.

We have also sequenced 497 bp on the $5^{\prime}$ side and $285 \mathrm{bp}$ on the $3^{\prime}$ end of the left-hand copy of IS1246 (Fig. 1) and 264 bp on the $5^{\prime}$ side and 221 bp on the $3^{\prime}$ side of the righthand copy and within these flanking regions have located one end of the $x y l$ genes. At bases 259-264 on the 3' side of the right-hand IS1246 is the HpaII site at the beginning of the sequence identified as the upstream activator region for the $x y l C M A B N$ operon (Inouye $e t$ al., 1984): this site is $208 \mathrm{bp}$ upstream of the start of transcription of the operon. At the other end of the region between the repeats (i.e. $5^{\prime}$ of the right-hand IS1246) we were unable to find any homology with published sequences around the $x y / R$ gene, so this direct repeat lies more than 264 bases from the $x y l$ coding region. Restriction maps indicate that this distance is considerably larger, about $3 \mathrm{kbp}$ (Fig. 1).

\section{ACKNOWLEDGEMENTS}

This work was carried out when B. R. R. was on leave from Sri Krishnadevaraya University on a Fellowship from the As- sociation of Commonwealth Universities. The computer analyses were performed using the Seqnet facility, Daresbury, UK.

\section{REFERENCES}

Altschul, S. F., Gish, W., Miller, W., Myers, E. W. \& Lipman, D. J. (1990). Basic local alignment search tool. J Mol Biol 215, 403-410.

Assinder, S. J. \& Williams, P.A. (1990). The TOL plasmids: determinants of the catabolism of toluene and the xylenes. $A d v$ Microb Physiol 31, 1-69.

Bairoch, A. (1993). The Prosite dictionary of sites and patterns in proteins; its current status. Nucleic Aiids Res 21, 3097-3103.

Bayley, S. A., Duggleby, C. J., Worsey, M. J., Williams, P. A., Hardy, K. G. \& Broda, P. (1977). Two modes of loss of the Tol functions from Pseudomonas putida mt-2. Mol \& Gen Genet 154, 203-204.

Devereux, J., Haeberli, P. \& Smithies, O. (1984). A comprehensive set of sequence analysis programs for the VAX. Nucleic. Acids Res 12, 387-395.

Downing, R. G., Duggleby, C. J., Villems, R. \& Broda, P. (1979). An endonuclease map of the plasmid pWW0-8, a derivative of the TOL plasmid of Pseudomonas putida mt-2. Mol \& Gen Genet 177, 97-99.

Inouye, S., Ebina, Y., Nakazawa, A. \& Nakazawa, T. (1984). Nucleotide sequence surrounding transcription initiation site of $x y l A B C$ operon on TOL plasmid of Pseudomonas putida. Proc Natl Acad Sci US A 81, 1688-1691.

Knight, A. I., Ni, H., Cartwright, K. A. V. \& McFadden, J. J. (1992). Identification and characterization of a novel insertion sequence IS1106 downstream of the por $A$ gene in B15 Neisseria meningitidis. Mol Microbiol 6, 1565-1573.

Kröger, M. \& Hobom, G. (1982). Structural analysis of insertion sequence IS5. Nature 297, 159-162.

Kunz, D. A. \& Chapman, P. J. (1981). Catabolism of pseudocumene and 3-ethyl toluene by Pseudomonas putida (arvilla) $\mathrm{mt}-2$ : evidence for new functions of the TOL (pWW0) plasmid. J Bacteriol 146, 179-191.

Meulien, P., Downing, R. G. \& Broda, P. (1981). Excision of the $40 \mathrm{~kb}$ segment of the TOL plasmid from Pseudomonas putida $\mathrm{mt}-2$ involves direct repeats. Mol \& Gen Genet 184, 97-101.

Tsuda, M. \& lino, T. (1987). Genetic analysis of a transposon carrying toluene degrading genes on TOL plasmid pWW0. Mol \& Gen Genet 210, 270-276.

Tsuda, M. \& lino, T. (1988). Identification and characterisation of Tn4653, a transposon covering the toluene transposon Tn4651 on TOL plasmid pWW0. Mol \& Gen Genet 213, 72-77.

Tsuda, M., Minegishi, K-I. \& lino, T. (1989). Toluene transposons Tn4651 and Tn4653 are class II transposons. J Bacteriol 171, 1386-1393.

Worsey, M. J. \& Williams, P. A. (1975). Metabolism of toluene and xylenes by Pseudomonas putida (arvilla) $\mathrm{mt}-2$ : evidence for a new function of the TOL plasmid. $J$ Bacteriol 124, 7-13.

Received 2 March 1994; revised 18 April 1994; accepted 28 April 1994. 